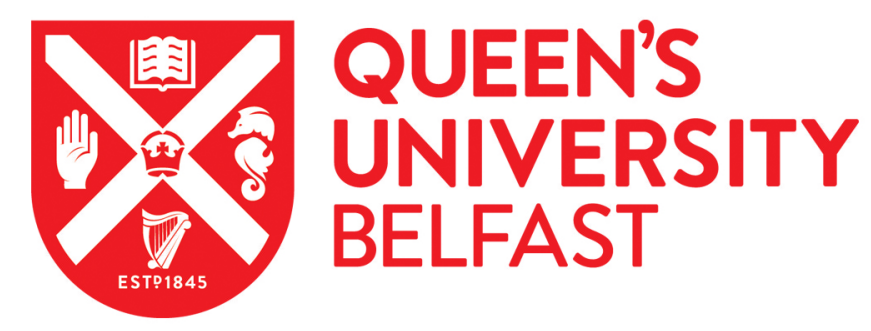

\title{
Exogenous Drivers of Bitcoin and Cryptocurrency Volatility - A Mixed Data Sampling Approach to Forecasting
}

Walther, T., Klein, T., \& Bouri, E. (2019). Exogenous Drivers of Bitcoin and Cryptocurrency Volatility - A Mixed Data Sampling Approach to Forecasting. Journal of International Financial Markets, Institutions and Money. https://doi.org/10.1016/j.intfin.2019.101133

Published in:

Journal of International Financial Markets, Institutions and Money

Document Version:

Peer reviewed version

Queen's University Belfast - Research Portal:

Link to publication record in Queen's University Belfast Research Portal

Publisher rights

Copyright 2019 Elsevier

This manuscript is distributed under a Creative Commons Attribution-NonCommercial-NoDerivs License

(https://creativecommons.org/licenses/by-nc-nd/4.0/), which permits distribution and reproduction for non-commercial purposes, provided the author and source are cited.

\section{General rights}

Copyright for the publications made accessible via the Queen's University Belfast Research Portal is retained by the author(s) and / or other copyright owners and it is a condition of accessing these publications that users recognise and abide by the legal requirements associated with these rights.

Take down policy

The Research Portal is Queen's institutional repository that provides access to Queen's research output. Every effort has been made to ensure that content in the Research Portal does not infringe any person's rights, or applicable UK laws. If you discover content in the Research Portal that you believe breaches copyright or violates any law, please contact openaccess@qub.ac.uk. 


\title{
Exogenous Drivers of Bitcoin and Cryptocurrency Volatility - A Mixed Data Sampling Approach to Forecasting ${ }^{\text {色 }}$
}

\author{
Thomas Walther ${ }^{\mathrm{a}, \mathrm{b}, \mathrm{c}, *}$, Tony Klein ${ }^{\mathrm{d}}$, Elie Bouri ${ }^{\mathrm{e}}$ \\ ${ }^{a}$ Utrecht School of Economics, Utrecht University, The Netherlands \\ ${ }^{b}$ Institute for Operations Research and Computational Finance, University of St. Gallen, Switzerland \\ ${ }^{c}$ Faculty of Business and Economics, Technische Universität Dresden, Germany \\ ${ }^{d}$ Queen's Management School, Queen's University Belfast, UK \\ ${ }^{e}$ Holy Spirit University of Kaslik (USEK), USEK Business School, Jounieh, Lebanon
}

\begin{abstract}
We apply the GARCH-MIDAS framework to forecast the daily, weekly, and monthly volatility of five highly capitalized Cryptocurrencies (Bitcoin, Etherium, Litecoin, Ripple, and Stellar) as well as the Cryptocurrency index CRIX. Based on the prediction quality, we determine the most important exogenous drivers of volatility in Cryptocurrency markets. We find that the Global Real Economic Activity outperforms all other economic and financial drivers under investigation. We also show that the Global Real Economic Activity provides superior volatility predictions for both, bull and bear markets. In addition, the average forecast combination results in low loss functions. This indicates that the information content of exogenous factors is time-varying and the model averaging approach diversifies the impact of single drivers.
\end{abstract}

Keywords: Bitcoin, Cryptocurrencies, GARCH, Mixed Data Sampling, Volatility JEL classification: C10; C58; G11

\footnotetext{
We thank the editors Jonathan Batten and Harald Kinateder and two anonymous reviewers for valuable suggestions which led to an improvement of this article. Please cite the article as follows: Walther, Thomas; Klein, Tony; Bouri, Elie (2019): Exogenous Drivers of Bitcoin and Cryptocurrency Volatility - A Mixed Data Sampling Approach to Forecasting, in: Journal of International Financial Markets, Institutions \& Money, forthcoming. DOI: 10.1016/j.intfin.2019.101133.

*Corresponding Author, Mail: thomas.walther@tu-dresden.de
} 


\section{Introduction}

Focusing on the anatomy of volatility by identifying relevant exogenous drivers is important for financial market participants and policy makers who are concerned with refining the volatility prediction of asset prices for the sake of risk assessment, risk mitigation, and the formulation of regulatory policies. Remarkably, there is a large body of research examining the role of macro-economic and financial variables in predicting the volatility of equities (e.g. Schwert, 1989, Paye, 2012) and other assets such as bonds, foreign exchange, and commodities (e.g. Christiansen et al., 2012).

With the growing popularity of Cryptocurrencies as a new digital asset class in recent years, identification of the factors driving the volatility of Cryptocurrencies has become an important research topic (Corbet et al., 2018a). Cryptocurrencies are characterized by extreme high and persistent volatility (Chu et al., 2017, Katsiampa, 2017) that exceeds the volatility of other assets like equities and gold (Klein et al., 2018, Baur et al., 2018b). Accordingly, investors and traders in the Cryptocurrency market are eager to refine their knowledge of the determinants of volatility for the sake of risk and portfolio management. However, the related literature provides inconclusive findings and is generally limited in regard to the coverage of Cryptocurrencies, the drivers of volatility, and the methods used.

Previous studies consider the volatility of Bitcoin ${ }^{1}$ using GARCH-based models and mostly predict Bitcoin volatility based only on past returns as conditional information (e.g. Katsiampa, 2017). Other internal drivers of Bitcoin volatility have also been studied. Kristoufek (2015) analyzes various drivers of Bitcoin prices and volatility based on a wavelet approach. He finds that Bitcoin shows signs of a classical currency with supply and price level being main drivers of volatility along with a sentiment component. These internal drivers are also examined by Baek \& Elbeck (2015) who do not identify any exogenous drivers in the early years of price development in the Bitcoin market. Furthermore, Balcilar et al. (2017) show that trading volume is not useful to predict Bitcoin

\footnotetext{
${ }^{1}$ There is a vast literature on the price determinants of the original Cryptocurrency, Bitcoin, based on the of the information contents of macro-economic and financial variables (see, among others, Kristoufek, 2015, Bouri et al., 2017b, Baumöhl, 2019, Bouri et al., 2018a b, Corbet et al., 2018a, Demir et al., 2018, Panagiotidis et al. 2018).
} 
volatility: $:^{2}$ Interestingly, some other studies focus on Bitcoin volatility while considering exogenous macro-economic and financial variables such as equity indices (Dyhrberg, 2016), equity market volatility (Bouri et al., 2017a, Charfeddine \& Maouchi, 2019), currencies (Dyhrberg, 2016), and commodities such as gold (Dyhrberg, 2016). However, most of those studies focus on Bitcoin only and test predictability within GARCH models. These GARCH models require the frequency of explanatory variables to match that of the predicted (volatility) variable (i.e., daily vs daily, weekly vs daily, or monthly vs monthly), which unfortunately constrains the choice of the potential explanatory variables. Furthermore, those studies are restricted to specific investment horizons like days or months and are conducted with in-sample analysis.

In this paper, we examine the macro-economic and financial factors driving the volatility of not only Bitcoin but other leading Cryptocurrencies (i.e., Ethereum, Litecoin, Ripple, and Stellar) as well as the Cryptocurrency index CRIX (Trimborn \& Härdle, 2018). Importantly, our methodology is founded on the GARCH-mixed data sampling (GARCHMIDAS) approach of Engle et al. (2013), which allows not only the use of explanatory variables with various frequencies (i.e., daily and monthly), but also differentiation between short-term and long-term volatility components $!^{3}$ We also conduct out-of-sample analyses, consider various forecasting horizons (i.e., day, week, and month), and extend some of the analyses to the time-varying case. Such a rich examination adds to the strand of research that focuses only on in-sample perspective and performance in terms of goodness-of-fit (Dyhrberg, 2016, Catania \& Grassi, 2017, Chu et al., 2017, Corbet et al., 2018b, Katsiampa, 2017, Ardia et al., 2019, Peng et al., 2018, Phillip et al., 2018, Baur et al., 2018a, Klein et al., 2018).

Studying the factors driving the volatility of Bitcoin and other leading Cryptocurrencies via the GARCH-MIDAS approach is important and of relevance to investors and traders in the Cryptocurrency market for several reasons. First, no consensus exists on

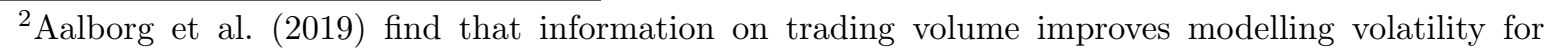
Bitcoin.

${ }^{3}$ Notably, the explanatory variables enter into the specification of the long-term volatility component of the GARCH-MIDAS model.
} 
the factors determining the volatility of Bitcoin. This is probably due to the restriction of choice of potential explanatory variables based on a single frequency, such as daily, whereas other key variables such as the Global Economic Policy Uncertainty index and Global Real Economic Activity are only available at the monthly frequency. Therefore, the use of a GARCH-MIDAS approach allows us to extend the existing literature by including important variables at various daily and monthly frequencies. Second, the application of the GARCH-MIDAS model helps differentiate between short-term and long-term components of volatility and their determinants. This is useful for market participants in the Cryptocurrency market who generally prefer to match different trading and investment strategies to their investment horizons. For example, traders have short term investment horizons, which makes them concerned with short term volatility, while investors have long term investment horizons and are therefore more concerned with long term volatility and its determinants. Third, the application of the GARCH-MIDAS model to the determinants of volatility in the markets of Bitcoin and other Cryptocurrencies helps reconcile contradicting findings and refine the knowledge of traders and investors for their decision making.

The GARCH-MIDAS approach, which was initially applied into the broad finance and economics literature by Engle et al. (2013), has been recently prolonged into the literature on Bitcoin finance. Using the GARCH-MIDAS approach, Fang et al. (2019) provide evidence that global economic policy uncertainty enhances the hedging effectiveness of Bitcoin and the prediction of Bitcoin volatility, while Conrad et al. (2018) explore the factors driving Bitcoin's volatility and provide evidence that Bitcoin volatility is closely linked to global economic activity:5

Our current paper is more related to Conrad et al. (2018), but differs in several respects. First, while Conrad et al. (2018) focus on Bitcoin, we examine Bitcoin and four other leading Cryptocurrencies (Ethereum, Litecoin, Ripple, and Stellar) that have been

\footnotetext{
${ }^{4}$ Remarkably, Katsiampa (2017) presents evidence that Bitcoin volatility can be decomposed into long and short-term components.

${ }^{5}$ The authors state that their results suggest the superiority of GARCH-MIDAS over the simple GARCH model for forecasting Bitcoin volatility.
} 
eroding the dominance of Bitcoin over the Cryptocurrency market and becoming serious competitors and alternative digital investments. We also consider the broad Cryptocurrency index CRIX. Second, we use broad range of possible economic and financial variables which might influence the volatility of major Cryptocurrencies. These include the Global Financial Stress Index (Bouri et al., 2018b), global and Chinese economic policy uncertainty (Demir et al., 2018), and crude oil (Hayes, 2017). Third, and unlike Conrad et al. (2018) who use an in-sample analysis and compare information criteria of models with an identical number of parameters which makes a penalization irrelevant, we conduct a pseudo-out-of-sample and forecasting analysis over various time horizons to overcome this issue with the cost of less predictive power (Diebold, 2015, Hansen, 2010). We also conduct a rolling analysis to assess the stability of the forecast errors over time.

Our empirical analyses are not only useful to investors for the construction of improved forecasts of long-term volatility in the Cryptocurrency market but to policy-makers concerned about market efficiency in this young Cryptocurrency market. This makes our paper related to the literature on the efficiency of financial markets in general Malkiel, 1989) and the Cryptocurrency market in particular (see, among others, Urquhart, 2016, Nadarajah \& Chu, 2017, Bariviera et al., 2017, Kristoufek, 2018, Alaoui et al., 2018). The fact that the Cryptocurrency market is much younger than the equity market could have an adverse effect on the market efficiency of the various Cryptocurrencies under study, leading to potential predictability. This is interesting, as recent empirical evidence on the efficiency of Bitcoin and other Cryptocurrencies provides a mixed picture and in some cases evidence that market efficiency varies over time. In an early study, Baek \& Elbeck (2015) find no evidence of predictability, whereas later studies report contradicting evidence (Urquhart, 2016, Nadarajah \& Chu, 2017, Bariviera, 2017, Kristoufek, 2018, Sensoy, 2019), which suggest the possibility to predict Bitcoin volatility.6

Lastly, our work is related to research on the usefulness of Cryptocurrencies for in-

\footnotetext{
${ }^{6}$ This contradicts the view on the transition of the Cryptocurrency market and its progress toward maturity. Some might argue that the design and integrity of the underlying distributed ledger technology and the digital-only presence of the markets has led to a tremendous growth and maturing of these markets in the past years.
} 
vestors and the benefits of adding Cryptocurrencies to traditional portfolios Anyfantaki et al., 2018, Petukhina et al., 2018, Trimborn et al., 2019). Our findings contribute to understanding the time-varying drivers of volatility of this new asset class which heavily influences the success of portfolio allocation strategies.

Our main results show that the volatility in the Cryptocurrency market is not detached from economic fundamentals, but it is more driven by global economic and financial factors than country-specific ones. Generally, our results concur with the results of Conrad et al. (2018) and Fang et al. (2019) regarding Bitcoin.

The methodology is outlined in Section 2. Price data is summarized in Section 3 while the results are discussed in Section 4 . Important implications are presented in Section 5.

\section{Methodology}

In this section, we introduce the models to forecast the volatility of Cryptocurrencies based on the well known autoregressive conditional heteroskedasticity models. The standard GARCH(1,1) process (Engle, 1982, Bollerslev, 1986) builds on the squared innovations of the return series $r_{t}$ to model the returns' volatility $\sqrt{h_{t}}$ and reads as follows:

$$
\begin{aligned}
r_{t} & =\mu+\varepsilon_{t} \quad \text { with } z_{t} \sim t_{\nu}(0,1) \text { i.i.d., } \\
\varepsilon_{t} & =z_{t} \sqrt{h_{t}} \\
h_{t} & =\omega+\alpha \varepsilon_{t-1}^{2}+\beta h_{t-1} .
\end{aligned}
$$

Here, $\mu$ is the unconditional mean and $\varepsilon_{t}$ the scaled innovation of the return series. As suggested by Klein et al. (2018), we use Student's $t$ distributed innovations $z_{t}$ for the model to account for the non-normal returns of Cryptocurrencies. Moreover, the parameter $\omega$ describes a constant long-term variance, $\alpha$ the impact of the scaled, squared innovations, and $\beta$ the auto-regressive impact of the past variance. Following, the unconditional variance of the standard GARCH model is $\mathbb{E}\left[r_{t}^{2}\right]=\frac{\omega}{1-\alpha-\beta}$ for the given case of a $\operatorname{GARCH}(1,1)$. Thus, the conditions for non-negativity and stationarity include $\omega, \alpha, \beta>0$ 
and $(1-\alpha-\beta)>0$. This process, however, does not incorporate external explanatory variables which might further explain the volatility of the underlying return process.

The GARCH-MIDAS model (Engle et al., 2013) disentangles the volatility into a shortterm $\left(g_{t, m}\right)$ and a long-term component $\left(\tau_{m}\right)$ and roots in the Component- and SplineGARCH models (Engle \& Lee, 1999, Engle \& Rangel, 2008). The process explicitly allows for further explanatory variables to model the time-varying long-term volatility component. While the $g_{t, m}$ is a standard $\operatorname{GARCH}(1,1)$ process, $\tau_{m}$ is described by means of the MIDAS technique and involves data of lower frequency. The full model for the daily Cryptocurrency returns reads as follows:

$$
\begin{aligned}
r_{t, m} & =\mu+\varepsilon_{t, m} \\
\varepsilon_{t, m} & =z_{t, m} \sqrt{\tau_{m} g_{t, m}} \quad \text { with } z_{t, m} \sim t_{\nu}(0,1) \text { i.i.d., } \\
g_{t, m} & =(1-\alpha-\beta)+\alpha\left(\frac{\varepsilon_{t-1, m}^{2}}{\tau_{m}}\right)+\beta g_{t-1, m}, \\
\tau_{m} & =\exp \left(c+\theta \sum_{k=1}^{K} \varphi_{k}\left(\omega_{1}, \omega_{2}\right) X_{m-k}\right), \\
\varphi_{k}\left(\omega_{1}, \omega_{2}\right) & =\frac{(k /(K+1))^{\omega_{1}-1}(1-k /(K+1))^{\omega_{2}-1}}{\sum_{j=1}^{K}(j /(K+1))^{\omega_{1}-1}(1-j /(K+1))^{\omega_{2}-1}},
\end{aligned}
$$

where $\mu$ is the unconditional mean, $t$ and $m$ are the indices for the days and months, and $X_{m}$ is the explanatory variable at monthly frequency. For the short-term GARCH process $g_{t, m}$ the standard non-negativity and stationarity constrains have to hold. Wang \& Ghysels (2015) further discuss the stationarity conditions for GARCH-MIDAS. To weight the lagged low-frequency variables, we use the Beta-weighting scheme $\varphi_{k}\left(\omega_{1}, \omega_{2}\right)$ introduced by Ghysels et al. (2007). It is straightforward that the model decomposes to the standard GARCH model if $\theta=0$ in Eq. (7). Here, we employ monthly explanatory variables to describe the long-term component of the daily conditional volatility of Cryptocurrencies and set $K=12$, which translates in incorporating the last twelve monthly observations of the explanatory variable.

We forecast the 1-day, 7-days, and 30-days ahead variance of $h_{t, m}=\tau_{m} g_{t, m}$ by estimating the parameters of the model for a rolling window $t=1, \ldots, T$ and predicting the 
next period's variance. For 1-day ahead, the predicted variance is:

$$
\hat{h}_{T+1, M}=\tau_{M}\left((1-\alpha-\beta)+\alpha\left(\frac{\varepsilon_{T, M}^{2}}{\tau_{M}}\right)+\beta g_{T, M}\right)
$$

where $M$ is the corresponding month to $T$. In order to predict the 7 -days and 30-days ahead variance, i.e. $s=7$ and $s=30$, we conducted a recursive substitution of the unknown variance forecast back to time $T$ :

$$
\hat{h}_{T+s, M}=\tau_{M}\left((1-\alpha-\beta) \sum_{i=0}^{s}(\alpha+\beta)^{i}+(\alpha+\beta)^{s} g_{T, M}\right) \text {. }
$$

Note that our estimate for the future long-term variance $\tau$ is the last element of the insample regression, namely $\tau_{M}$. Doing so, we avoid to forecast each exogenous variable. Moreover, it allows the last available information of the exogenous variable to affect also the short-term forecasts. Ederington \& Guan (2010) criticize the way of substitute the variance forecasts recursively. The authors show that keeping the same relative weights for more recent and older observations might affect forecasts of longer horizons negatively. However, as outlined in Nguyen \& Walther (2019), the long-term component of GARCHMIDAS affects the overall volatility including forecast of longer horizons.

We evaluate the forecast by means of the Heteroskedasticity-adjusted Mean Squared Error (HMSE)

$$
\operatorname{HMSE}=N^{-1} \sum_{i=1}^{N}\left(1-\left(r_{i, m}-\hat{\mu}\right)^{2} / \hat{h}_{i, m}\right)^{2},
$$

and the Heteroskedasticity-adjusted Mean Absolute Error (HMAE)

$$
\mathrm{HMAE}=N^{-1} \sum_{i=1}^{N}\left|1-\left(r_{i, m}-\hat{\mu}\right)^{2} / \hat{h}_{i, m}\right|
$$

The two measures are often used to evaluate GARCH models (e.g. Bollerslev \& Ghysels, 1996, Patton, 2011). Based on the Model Confidence Set (MCS, Hansen et al., 2011), we derive a set of models outperforming the other models which are not an elements of the respective MCS. Following Hansen et al. (2011), we calculate two different sets, namely the $90 \%$ and $75 \%$ confidence sets. We use the $\operatorname{GARCH}(1,1)$ model as a benchmark and 
also employ the average forecast combination of all GARCH-MIDAS models $(1 / \mathrm{n})$ as model averaging approach by

$$
\hat{h}_{i, m}=|P|^{-1} \sum_{p \in P} \hat{h}_{i, m}^{p}
$$

where $P$ is the set of all models under investigation.

\section{Data}

We employ time series of prominent Cryptocurrencies, i.e. Bitcoin, Etherium, Litecoin, Stellar, and Ripple. All Cryptocurrency time series are retrieved from coinmarketcap. com. In addition, we use the Cryptocurrency index CRIX available from thecrix.de (Trimborn \& Härdle, 2018). All daily price series are sampled until July 31, 2019 but vary in their starting point. An overview of the respective sampling period and resulting total number of observations is given in Panel A of Tab. 1 along with selected descriptive statistics. We set the initial and rolling training sample to one year, i.e. 730 days. Consequently, we have varying lenghts of out-of-sample periods from 698 days (Etherium) to 1552 days (Bitcoin and Litecoin), representing roughly two to four years, respectively. An in-depth statistical overview of Cryptocurrencies is given in Härdle et al. (2018). Figure 1 presents the price movements of the selected Cryptocurrencies in our sample period.

In order to explain the long-term volatility component in the GARCH-MIDAS setup, we utilize various financial and economic time series which are given in Panel B of Tab. 1. In particular, we use the monthly returns and realized volatility of the S\&P 500, the MSCI Emerging Markets 50 (MSCI EM), the Dow Jones Precious Metals (DJPM) index, and the Crude Oil Front Month Futures of the West Texas Intermediate (WTI) in order to investigate the impact of the U.S. and Emerging Markets, especially Chinese, equity markets as well as the influence of commodities. Additionally, we employ the CBOE implied volatility index of the S\&P 500 (VIX) as well as the Bank of America Merryl Lynch Global Financial Stress Index (GFSI) to cover for possible spillovers of 
financial volatility $\left.\right|^{7}$ In terms of economic variables, we include the Global (Current) and the Chinese (South China Morning Post) Economic Policy Uncertainty index (GEPU and CEPU, www.policyuncertainty.com) as well as the Global Real Economic Activity (GREA) ${ }^{8}$, and the trade weighted USD index (fred.stlouisfed.org/series/DTWEXM).

For the financial variables we use monthly logarithmic returns (logRet) and the monthly realized volatility $R V_{m}=\sum_{t=1}^{M} r_{t, m}^{2}$. We keep GFSI, the volatility index VIX, and GREA at levels. The two Economic Policy Uncertainty indices are used as simple returns (sRet).

$$
\begin{aligned}
& \text { [include Table } 1 \text { about here] } \\
& \text { [include Figure } 1 \text { about here] }
\end{aligned}
$$

\section{Results}

\subsection{Out-of-sample forecast results}

We use the presented exogenous drivers of the long-term volatility to forecast the conditional volatility of Bitcoin, Etherium, Litecoin, Ripple, Stellar, and CRIX. The forecast horizon is set to one day, one week, and one month, i.e. 1-day, 7-days, and 30days ahead forecasts since Cryptocurrencies are traded continuously.

Table 2 presents the results for the two loss functions. We do not find a single driver which is consistently outperforming its peers over the cross-section of Cryptocurrencies and forecasting horizons. Hence, each Cryptocurrency tends to have a specific exogenous variable which results in the lowest corresponding loss function. Over all 1-day ahead forecasts, we find GEPU to best predict Bitcoin, DJPM RV for Etherium, GFSI for Litecoin, GREA for Ripple and CRIX, and CEPU for Stellar. These drivers lead to both the lowest HMSE and HMAE. However, the choice of exogenous variable varies over different forecast horizons.

\footnotetext{
${ }^{7}$ Except for the GFSI, all variables are retrieved from Thomson Reuters DataStream. The data for the GFSI is gathered from Bloomberg Terminal.

${ }^{8}$ We are thankful to Lutz Kilian for providing the updated data on his website (https://sites . google.com/site/lkilian2019/research/data-sets). The construction is described in detail in Kilian (2009, 2019).
} 
From the set of exogenous variables, GREA, GFSI, CEPU, and the S\&P 500 RV result in the most inclusions of the $90 \%$ and $75 \%$ MCS. In total, GREA (GFSI, CEPU, and S\&P 500 RV) appear to be included $21(14,16,12)$ times in the $75 \%$ MCS and even $26(19,17,20)$ times in the $90 \%$ MCS out of 36 possibilities.$^{9}$ This is interesting, since the next best choices only result in 10 and 13 appearances, respectively for the $75 \%$ and 90\% MCS. This finding indicates that GREA - a proxy for the world's business cycle - is a very robust predictor of Cryptocurrencies' volatility over their cross-section. Moreover, the GSFI and the RV of the S\&P 500, both indicators of financial stress, also provide information important for forecasts. Remarkably, the Economic Policy Uncertainty of China is among the best predictors, showing that not only China (Ciaian et al., 2017), but also policy uncertainty is important in Cryptocurrency markets (Demir et al., 2018, Fang et al., 2019). We note that our benchmark model, the basic $\operatorname{GARCH}(1,1)$ does a very poor job and is only included 3 and 7 times over all 36 possibilities. Even more astonishing is the finding that common choices of volatility drivers of other asset classes, in particular VIX (8 and 12) or the WTI logRet (5 and 2), do not predict the volatility of Cryptocurrencies sufficiently, especially not for shorter horizons. Figure 2 illustrates the fitted long-term component of GREA for the Bitcoin time series in comparison to the constant long-term volatility of the simple GARCH. After 2014, GREA seems able to model the long-term mean, around which the short-term component is fluctuating. However, the simple GARCH only provides some kind of baseline.

Comparing our forecasting results with the in-sample results of earlier studies, we can confirm the findings of Conrad et al. (2018) for Bitcoin, that macroeconomic business cycle indicator and the S\&P 500 RV contain important information for Cryptocurrency volatility. The authors employ the Baltic Dry index which is somewhat similar to Kilian's (2009) GREA. Interestingly, GREA also turns out to be of explanatory value for other commodities (Nguyen \& Walther, 2019). However, we cannot support the findings that the VIX is important for the volatility of Bitcoin. Moreover, we cannot conclude that the

\footnotetext{
${ }^{9}$ There are 36 possibilities rooting in three different forecasting horizons, six different Cryptocurrencies, and two different loss functions.
} 
US exchange rate, as suggested by Dyhrberg (2016), has some potential for forecasting Cryptocurrencies. Our results also reflect those of Bouri et al. (2018b). While the authors find evidence of dependency between the GFSI and Bitcoin returns, we can conclude that GFSI does also have predictive information for the long-run volatility.

The GARCH-MIDAS model with GREA as exogenous driver is the first-best choice in our sample. However, the second-best choice is not another single predictor, but the average forecast combination of all models under investigation. It is included in 17 (20) out of 36 different MCS for $90 \%$ (75\%) level of confidence. We conclude that the model averaging is an interesting alternative to single predictors, since it somewhat diversifies the forecasts at each point in time.

Based on several robustness checks, these results hold. In particular, we changed the lags of the MIDAS model to 36 months, used a GJR-GARCH to account for the wellknown leverage effect in the short-term dynamics as well as a change in the underlying return distribution to a Normal distribution.

\author{
[include Table 2 about here] \\ [include Figure 2 about here]
}

\title{
4.2. Further analysis based on rolling relative loss functions
}

To further illustrate the superiority of forecasts using GFSI, GREA, or the naive forecast combination, we provide the rolling relative HMSE and HMAE for the daily, weekly, and monthly volatility forecasts of Bitcoin in Fig. 35.5. Based on the rolling average 60-days HMSE and HMAE, the errors of S\&P500 RV, GFSI, GSCI RV, GREA, CEPU and the naive $1 / \mathrm{n}$ combination are plotted relative to the HMSE and HMAE of the simple GARCH. The idea is borrowed from Herrera et al. (2018) and allows us to evaluate the stability of the forecast errors over a given period. The first observation, i.e. the first average error is the mean of the first 60 single errors relative to the mean of the first 60 errors of the benchmark model (simple GARCH). The second average error is then the mean over the second single error to the 61 st and so on. 
It appears that the predictors have better forecasts errors relative to the simple GARCH most of the time. Especially, the naive forecast combination has better performance, with a few exceptions in 2015 and 2018. Additionally, we find that e.g. GREA performs equally well during bear and bull markets, if one compares the year 2015-2017 with 2018. On the contrary, the realized volatility of GSCI and the S\&P500 lose there relative superiority during the 2018 bear market.

Some of the explanatory variables, e.g. the realized volatility of the GSCI and the S\&P500 produce some extreme outliers in the relative performance especially for the longer-term forecasts of 7-days and 30-days ahead. It is noteworthy that these stepfunction like increases or decreases are caused by a single outlier which is then present in the 60-day error averages. This phenomenon with equity measures might be due to a lesser integration of Bitcoin with equity markets (Anyfantaki et al., 2018) and commodity markets (Ji et al., 2019a b $)$ in these times. A last important observation to be highlighted is the forecasting performance during bear market periods, shaded in grey in the plots. We find most of the exogenous predictors to perform much better than GARCH. This is of particular interest as GARCH is a short memory model and bear periods in Bitcoin markets are characterized by high volatilities, which should be picked up by simple GARCH-type models rather quickly. It appears that exogenous factors are better suited in predicting high volatilities during Bitcoin bear markets, which has direct implications for risk management.

Fig. 6, 8 visualize the relative forecasting performance for a broader Cryptocurrency index CRIX. Focusing on an index rather than a single coin might offer additional insight on forecasting performance. Similar to the findings for Bitcoin, we find exogenous predictors to outperform during bear market periods. Interestingly, during the turnaround after the bear period, almost all exogenous predictors perform relatively worse than GARCH. Another important observation is the forecasting performance with CEPU, the Chinese Policy Uncertainty index, which performs worse than GARCH but yields superior forecasts within a few days of the ex-post identified bear market. Chinese policy intervention for Cryptocurrency markets and closure of exchanges caused several violent market reac- 
tions with significant downturns across Cryptocurrencies. This highlights the sensitivity of Cryptocurrency markets to policy changes.

[include Figure 3 ,8 about here]

\section{Conclusions}

In this article, we investigate the usefulness of exogenous drivers to predict the 1-day, 7-days (one week), and 30-days (one month) ahead volatility of Cryptocurrencies. Out of a set of 17 different economic and financial drivers, we conclude that the Global Real Economic Activity outperforms its peers. The second best choice is the average forecast combination of all models under investigation. This is interesting for several reasons: Firstly, the volatility of Cryptocurrencies appears to be driven by the global business cycle rather than country-specific economic or financial variables. It shows that the large trading activity and market share in emerging markets do not have a steady effect on volatility of Cryptocurrency markets. Unforeseen policy changes, however, have a short-lived but significant impact. Secondly, the performance of the average forecasting combination suggests that even though Global Real Economic Activity is the best predictor on average, other exogenous variables, such as the Global Financial Stress Index or the Chinese Policy Uncertainty Index, contain useful information and diversify the impact. This underlines the hypothesis that given the decentralization of Cryptocurrency markets, there is not a single factor but rather a network of driving factors which interact with each other.

Future research could extend our work by re-investigating the issue with a different methodology, e.g. using intra-day data to construct daily realized volatility measures and adopt HAR-MIDAS as in Santos \& Ziegelmann (2014). Since we only use economic and financial variables, one could investigate whether the long-term volatility is driven by Cryptocurrency-specific drivers such as the realized volatility or the trading volume (Aalborg et al., 2019, Balcilar et al., 2017, Batten et al., 2019) 10 Moreover, it would be interesting to scrutinize the value-added of exogenous drivers for trading strategies, risk

\footnotetext{
${ }^{10}$ We intended to use the RV of the Cryptocurrencies to model the long-term volatility with GARCHMIDAS, but dropped the idea, since it shortened our sample and the available observations significantly.
} 
management, and portfolio allocation. Lastly, we only investigate the average forecast combination. Thus, an in-depth analysis of loss function minimizing forecast pooling would extend the literature. 


\section{References}

Aalborg, H. A., Molnár, P., \& de Vries, J. E. (2019). What can explain the price, volatility and trading volume of Bitcoin? Finance Research Letters, 29, 255-265. doi:10.1016/j.frl.2018.08.010.

Alaoui, M. E., Bouri, E., \& Roubaud, D. (2018). Bitcoin price-volume: A multifractal cross-correlation approach. Finance Research Letters, (pp. 1-8). doi:10.1016/j.frl. 2018.12.011.

Anyfantaki, S., Arvanitis, S., \& Topaloglou, N. (2018). Diversification, Integration and Cryptocurrency Market. URL: https://papers.ssrn.com/sol3/papers.cfm? abstract_id=3186474.

Ardia, D., Bluteau, K., \& Rüede, M. (2019). Regime changes in Bitcoin GARCH volatility dynamics. Finance Research Letters, 29, 266-271. doi:10.1016/j.frl.2018.08.009.

Baek, C., \& Elbeck, M. (2015). Bitcoins as an investment or speculative vehicle? A first look. Applied Economics Letters, 22, 30-34. doi:10.1080/13504851.2014.916379.

Balcilar, M., Bouri, E., Gupta, R., \& Roubaud, D. (2017). Can volume predict Bitcoin returns and volatility? A quantiles-based approach. Economic Modelling, 64, 74-81. doi:10.1016/j.econmod.2017.03.019.

Bariviera, A. F. (2017). The inefficiency of Bitcoin revisited: A dynamic approach. Economics Letters, 161, 1-4. doi:10.1016/j.econlet.2017.09.013.

Bariviera, A. F., Basgall, M. J., Hasperué, W., \& Naiouf, M. (2017). Some stylized facts of the Bitcoin market. Physica A: Statistical Mechanics and its Applications, 484, 82-90. doi:10.1016/j.physa.2017.04.159.

Batten, J. A., Kinateder, H., Szilagyi, P. G., \& Wagner, N. F. (2019). Liquidity, surprise volume and return premia in the oil market. Energy Economics, 77, 93-104. doi:10. $1016 / j$.eneco.2018.06.016.

Baumöhl, E. (2019). Are cryptocurrencies connected to forex? A quantile cross-spectral approach. Finance Research Letters, 29, 363-372. doi:10.1016/j.frl.2018.09.002.

Baur, D. G., Dimpfl, T., \& Kuck, K. (2018a). Bitcoin, gold and the US dollar - A replication and extension. Finance Research Letters, 25, 103-110. doi:10.1016/j. frl.2017.10.012.

Baur, D. G., Hong, K. H., \& Lee, A. D. (2018b). Bitcoin: Medium of exchange or speculative assets? Journal of International Financial Markets, Institutions and Money, 54, 177-189. doi:10.1016/j.intfin.2017.12.004.

Bollerslev, T. (1986). Generalized autoregressive conditional heteroskedasticity. Journal of Econometrics, 31, 307-327. doi:10.1016/0304-4076(86)90063-1.

Bollerslev, T., \& Ghysels, E. (1996). Periodic Autoregressive Conditional Heteroscedasticity. Journal of Business \& Economic Statistics, 14, 139-150. 
Bouri, E., Azzi, G., \& Haubo Dyhrberg, A. (2017a). On the return-volatility relationship in the Bitcoin market around the price crash of 2013. Economics: The OpenAccess, Open-Assessment E-Journal, 11, 1-17. doi:10.5018/economics-ejournal. ja.2017-2.

Bouri, E., Gupta, R., Lahiani, A., \& Shahbaz, M. (2018a). Testing for asymmetric nonlinear short- and long-run relationships between bitcoin, aggregate commodity and gold prices. Resources Policy, 57, 224-235. doi:10.1016/j.resourpol.2018.03.008.

Bouri, E., Gupta, R., Lau, C. K. M., Roubaud, D., \& Wang, S. (2018b). Bitcoin and global financial stress: A copula-based approach to dependence and causality in the quantiles. The Quarterly Review of Economics and Finance, 69, 297-307. doi:10.1016/j.qref. 2018.04.003.

Bouri, E., Jalkh, N., Molnár, P., \& Roubaud, D. (2017b). Bitcoin for energy commodities before and after the December 2013 crash: diversifier, hedge or safe haven? Applied Economics, 49, 1-11. doi:10.1080/00036846.2017.1299102.

Catania, L., \& Grassi, S. (2017). Modelling Crypto-Currencies Financial Time-Series. URL: https://www.ssrn. com/abstract=3028486. doi:10.2139/ssrn.3028486.

Charfeddine, L., \& Maouchi, Y. (2019). Are shocks on the returns and volatility of cryptocurrencies really persistent? Finance Research Letters, 28, 423-430. doi:10. $1016 / j . f r l .2018 .06 .017$.

Christiansen, C., Schmeling, M., \& Schrimpf, A. (2012). A comprehensive look at financial volatility prediction by economic variables. Journal of Applied Econometrics, 27, 956977. doi:10.1002/jae.2298.

Chu, J., Chan, S., Nadarajah, S., \& Osterrieder, J. (2017). GARCH Modelling of Cryptocurrencies. Journal of Risk and Financial Management, 10, 17. doi:10.3390/ jrfm10040017.

Ciaian, P., Rajcaniova, M., \& Kancs, D. (2017). Virtual relationships: Short- and longrun evidence from BitCoin and altcoin markets. Journal of International Financial Markets, Institutions and Money, 6, 467-486. doi:10.1016/j.intfin.2017.11.001.

Conrad, C., Custovic, A., \& Ghysels, E. (2018). Long-and Short-Term Cryptocurrency Volatility Components: A GARCH-MIDAS Analysis. Journal of Risk and Financial Management, 11, 1-12. doi:10.3390/jrfm11020023.

Corbet, S., Lucey, B., Urquhart, A., \& Yarovaya, L. (2018a). Cryptocurrencies as a financial asset: A systematic analysis. International Review of Financial Analysis, . doi:10.1016/j.irfa.2018.09.003.

Corbet, S., Meegan, A., Larkin, C., Lucey, B., \& Yarovaya, L. (2018b). Exploring the Dynamic Relationships between Cryptocurrencies and Other Financial Assets. Economics Letters, 165, 28-34. doi:10.1016/j.econlet.2018.01.004

Demir, E., Gozgor, G., Lau, C. K. M., \& Vigne, S. A. (2018). Does economic policy uncertainty predict the Bitcoin returns? An empirical investigation. Finance Research Letters, . doi:10.1016/j.frl.2018.01.005. 
Diebold, F. X. (2015). Comparing Predictive Accuracy, Twenty Years Later: A Personal Perspective on the Use and Abuse of Diebold-Mariano Tests. Journal of Business and Economic Statistics, 33. doi:10.1080/07350015.2014.983236.

Dyhrberg, A. H. (2016). Bitcoin, gold and the dollar - A GARCH volatility analysis. Finance Research Letters, 16, 85-92. doi:10.1016/j.frl.2015.10.008.

Ederington, L. H., \& Guan, W. (2010). Longer-term time-series volatility forecasts. Journal of Financial and Quantitative Analysis, 45, 1055-1076. doi:10.1017/ S0022109010000372.

Engle, R. F. (1982). Autoregressive Conditional Heteroscedasticity with Estimates of the Variance of United Kingdom Inflation. Econometrica, 50, 987-1007. doi:10.2307/ 1912773.

Engle, R. F., Ghysels, E., \& Sohn, B. (2013). Stock Market Volatility and Macroeconomic Fundamentals. Review of Economics and Statistics, 95, 776-797.

Engle, R. F., \& Lee, G. (1999). A long-run and short-run component model of stock return volatility. In R. Engle, \& H. White (Eds.), Cointegration, Causality, and Forecasting: A Festschrift in Honour of Clive W.J. Granger (pp. 475-497). Oxford: Oxford University Press.

Engle, R. F., \& Rangel, J. G. (2008). The spline-GARCH model for low-frequency volatility and its global macroeconomic causes. Review of Financial Studies, 21, 1187-1222. doi:10.1093/rfs/hhn004.

Fang, L., Bouri, E., Gupta, R., \& Roubaud, D. (2019). Does global economic uncertainty matter for the volatility and hedging effectiveness of Bitcoin? International Review of Financial Analysis, 61, 29-36. doi:10.1016/j.irfa.2018.12.010.

Ghysels, E., Sinko, A., \& Valkanov, R. (2007). MIDAS Regressions: Further Results and New Directions. Econometric Reviews, 26, 53-90. doi:10.1080/07474930600972467.

Hansen, P. R. (2010). A winner's curse for econometric models: on the joint distribution of in-sample fit and out-of-sample fit and its implications for model selection. URL: https://www.tse-fr.eu/sites/default/files/medias/stories/SEMIN_10_ 11/ECONOMETRIE/hansen.pdf.

Hansen, P. R., Lunde, A., \& Nason, J. M. (2011). The Model Confidence Set. Econometrica, 79, 453-497. doi:10.3982/ECTA5771.

Härdle, W. K., Harvey, C. R., \& Reule, R. C. G. (2018). Understanding Cryptocurrencies? URL: https://www.wiwi.hu-berlin.de/de/forschung/irtg/results/ discussion-papers/discussion-papers-2017-1/irtg1792dp2018-044.pdf.

Hayes, A. S. (2017). Cryptocurrency value formation: An empirical study leading to a cost of production model for valuing bitcoin. Telematics and Informatics, 34, 1308-1321. doi:10.1016/j.tele.2016.05.005.

Herrera, A. M., Hu, L., \& Pastor, D. (2018). Forecasting crude oil price volatility. International Journal of Forecasting, 34, 622-635. doi:10.1016/j.ijforecast.2018.04.007. 
Ji, Q., Bouri, E., Lau, C. K. M., \& Roubaud, D. (2019a). Dynamic connectedness and integration in cryptocurrency markets. International Review of Financial Analysis, 63, 257-272. doi:10.1016/j.irfa.2018.12.002.

Ji, Q., Bouri, E., Roubaud, D., \& Kristoufek, L. (2019b). Information interdependence among energy, cryptocurrency and major commodity markets. Energy Economics, 81, 1042-1055. doi:10.1016/j.eneco.2019.06.005.

Katsiampa, P. (2017). Volatility estimation for Bitcoin: A comparison of GARCH models. Economics Letters, 158, 3-6. doi:10.1016/j.econlet.2017.06.023.

Kilian, L. (2009). Not All Oil Price Shocks Are Alike: Disentangling Demand and Supply Shocks in the Crude Oil Market. American Economic Review, 99, 1053-1069. doi:10. 1257/aer.99.3.1053.

Kilian, L. (2019). Measuring global real economic activity: Do recent critiques hold up to scrutiny? Economics Letters, 178, 106-110. doi:10.1016/j.econlet.2019.03.001.

Klein, T., Pham Thu, H., \& Walther, T. (2018). Bitcoin is not the New Gold - A comparison of volatility, correlation, and portfolio performance. International Review of Financial Analysis, 59, 105-116. doi:10.1016/j.irfa.2018.07.010.

Kristoufek, L. (2015). What Are the Main Drivers of the Bitcoin Price? Evidence from Wavelet Coherence Analysis. PLOS ONE, 10, e0123923. doi:10.1371/journal.pone. 0123923.

Kristoufek, L. (2018). On Bitcoin markets (in)efficiency and its evolution. Physica A: Statistical Mechanics and its Applications, 503, 257-262. doi:10.1016/j.physa.2018. 02.161 .

Malkiel, B. G. (1989). Is the Stock Market Efficient? Science, 24, 1313-1318.

Nadarajah, S., \& Chu, J. (2017). On the inefficiency of Bitcoin. Economics Letters, 150, 6-9. doi:10.1016/j.econlet.2016.10.033.

Nguyen, D. K., \& Walther, T. (2019). Modeling and Forecasting Commodity Market Volatility with Long-term Economic and Financial Variables. Journal of Forecasting, . doi:10.1002/for. 2617 .

Panagiotidis, T., Stengos, T., \& Vravosinos, O. (2018). On the determinants of bitcoin returns: A LASSO approach. Finance Research Letters, 27, 235-240. doi:10.1016/j. frl.2018.03.016.

Patton, A. J. (2011). Volatility forecast comparison using imperfect volatility proxies. Journal of Econometrics, 160, 246-256. doi:10.1016/j.jeconom.2010.03.034.

Paye, B. S. (2012). 'Déjà vol': Predictive regressions for aggregate stock market volatility using macroeconomic variables. Journal of Financial Economics, 106, 527-546. doi:10. $1016 / j \cdot j$ fineco.2012.06.005.

Peng, Y., Albuquerque, P. H. M., Camboim de Sá, J. M., Padula, A. J. A., \& Montenegro, M. R. (2018). The best of two worlds: Forecasting high frequency volatility for cryptocurrencies and traditional currencies with Support Vector Regression. Expert Systems with Applications, 97, 177-192. doi:10.1016/j.eswa.2017.12.004. 
Petukhina, A., Trimborn, S., Härdle, W. K., \& Elendner, H. (2018). Investing With Cryptocurrencies: Evaluating the Potential of Portfolio Allocation Strategies. SSRN Electronic Journal, 49, 1-41. doi:10.2139/ssrn.3274193.

Phillip, A., Chan, J., \& Peiris, S. (2018). A new look at Cryptocurrencies. Economics Letters, 163, 6-9. doi:10.1016/j.econlet.2017.11.020.

Santos, D. G., \& Ziegelmann, F. A. (2014). Volatility forecasting via MIDAS, HAR and their combination: An empirical comparative study for IBOVESPA. Journal of Forecasting, 33, 284-299. doi:10.1002/for.2287.

Schwert, G. W. (1989). Why Does Stock Market Volatility Change Over Time? The Journal of Finance, 44, 1115-1153. doi:10.1111/j.1540-6261.1989.tb02647.x.

Sensoy, A. (2019). The inefficiency of Bitcoin revisited: A high-frequency analysis with alternative currencies. Finance Research Letters, 28, 68-73. doi:10.1016/j.frl.2018. 04.002 .

Trimborn, S., \& Härdle, W. K. (2018). CRIX an Index for cryptocurrencies. Journal of Empirical Finance, 49, 107-122. doi:10.1016/j.jempfin.2018.08.004.

Trimborn, S., Li, M., \& Härdle, W. K. (2019). Investing with Cryptocurrencies: A Liquidity Constrained Investment Approach. Journal of Financial Econometrics, (pp. 1-27). doi:10.1093/jjfinec/nbz016.

Urquhart, A. (2016). The inefficiency of Bitcoin. Economics Letters, 148, 80-82. doi:10. 1016/j.econlet.2016.09.019.

Wang, F., \& Ghysels, E. (2015). Econometric Analysis of Volatility Component Models. Econometric Theory, 31, 362-393. doi:10.1017/S0266466614000334. 


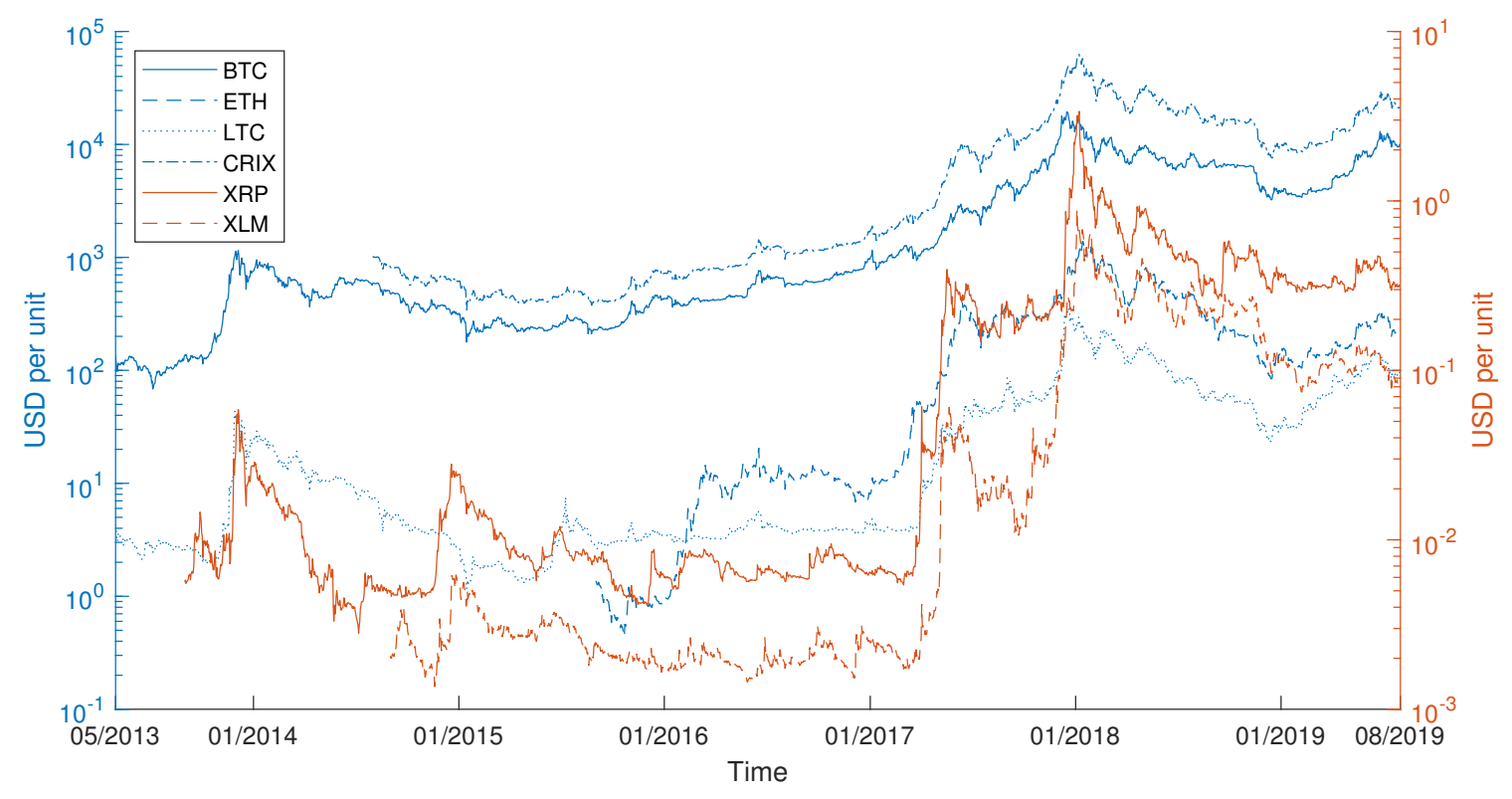

Figure 1: Prices of Bitcoin (BTC), Etherium (ETH), Litecoin (LTC), CRIX index points (CRIX), Ripple (XRP), and Stellar (XLM) in log-scale with their respective sampling range ending July 31, 2019.

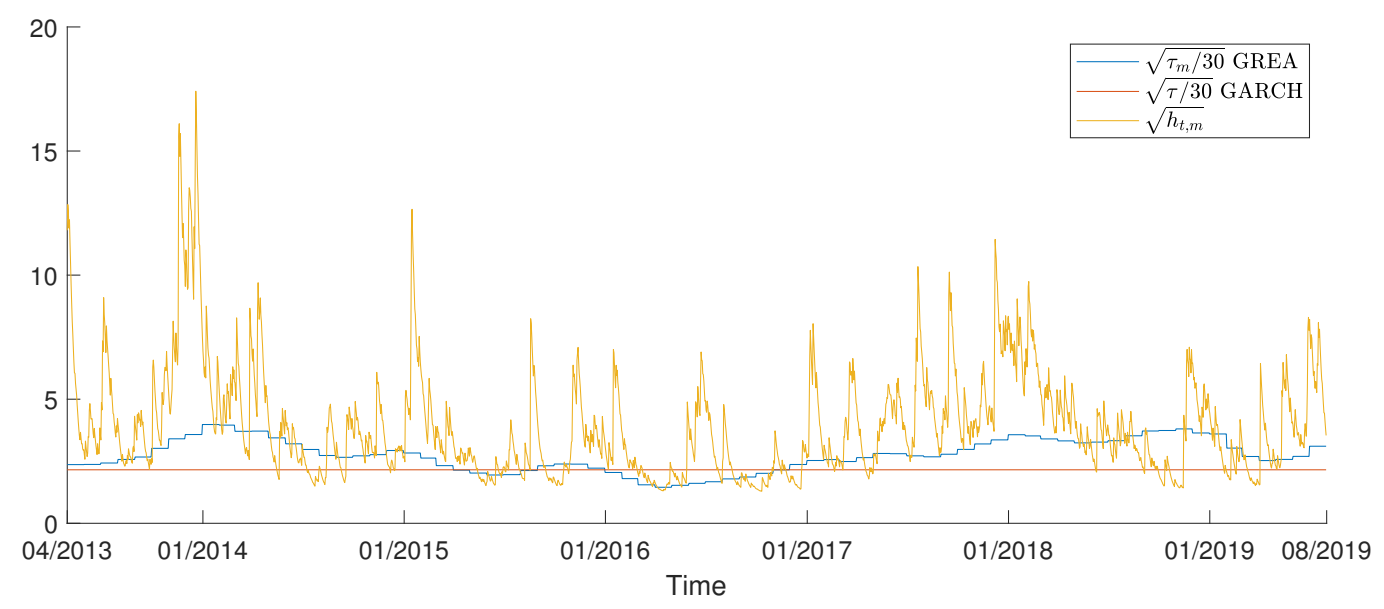

Figure 2: Daily volatility (yellow), daily long-term volatility component with GREA (blue), and VIX (red) for Bitcoin from May 1, 2013 to July 31, 2019. 

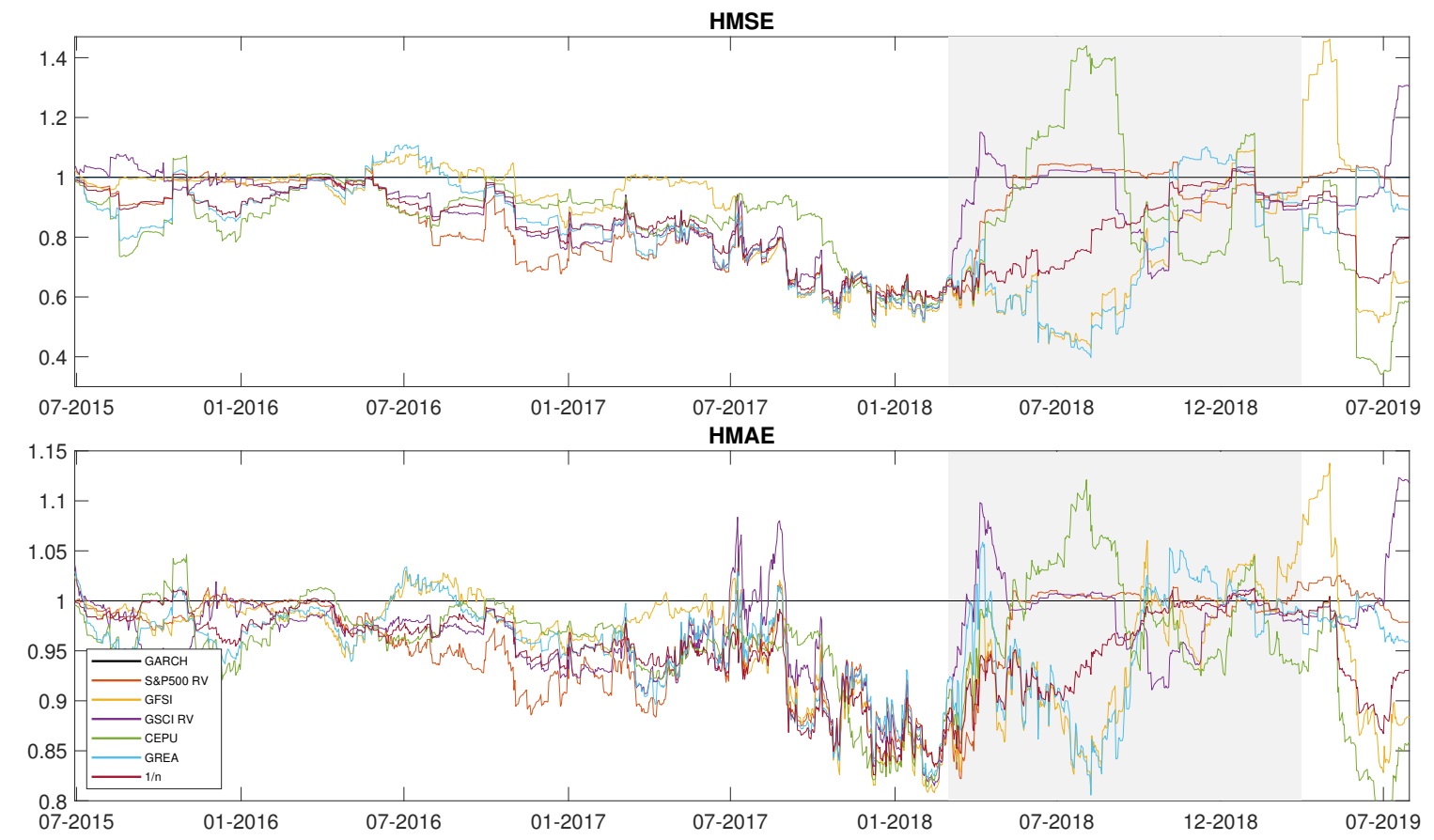

Figure 3: 60 days rolling window 1-day ahead relative HMSE and HMAE of Bitcoin with S\&P500 RV, GFSI, GSCI RV, CEPU, GREA, and the naive forecast combination. The errors are set relative to the simple GARCH prediction from June 29, 2015 to July 31, 2019. The "bear" market of 2018 to April 2019 is shaded in grey.
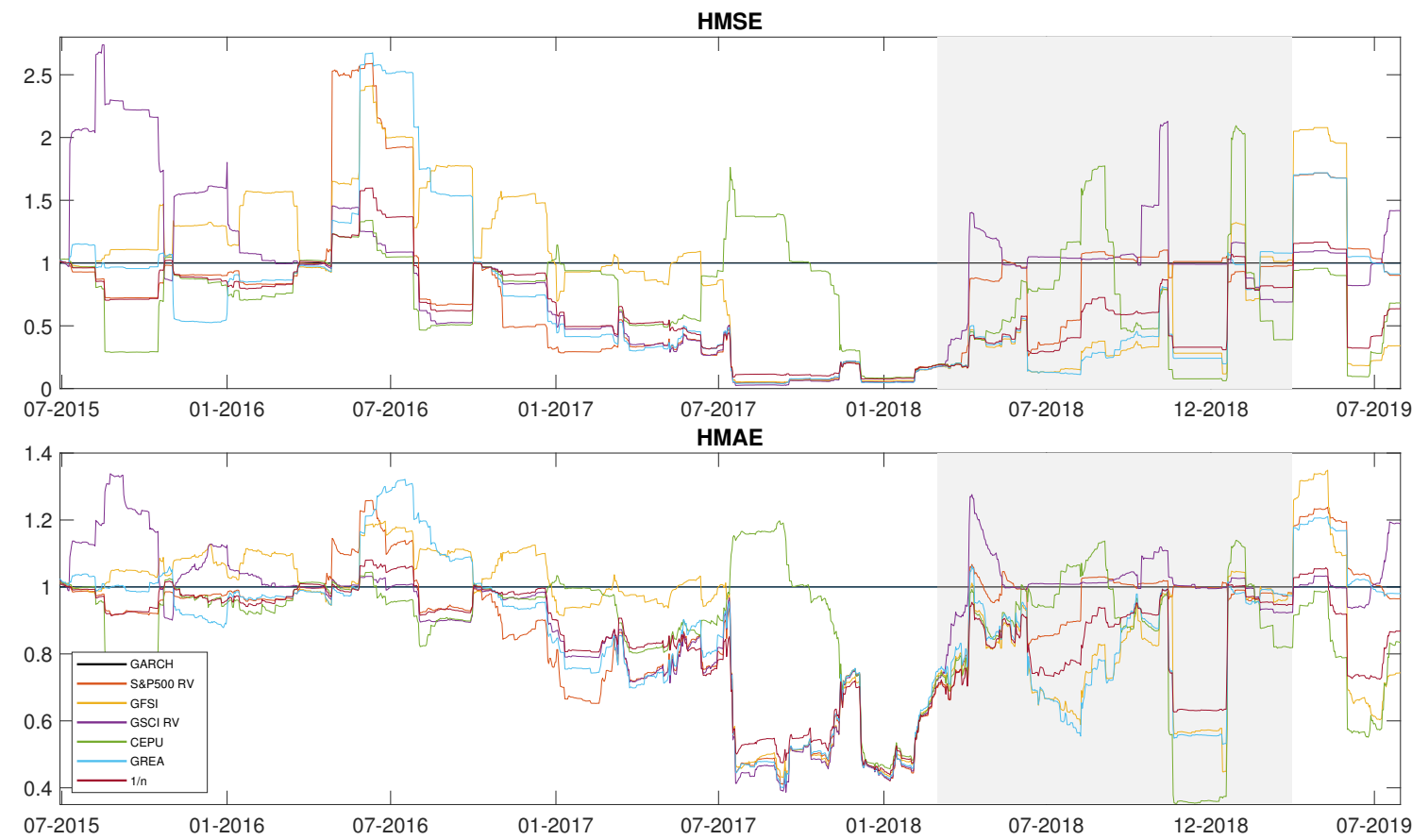

Figure 4: 60 days rolling window 7-days ahead relative HMSE and HMAE of Bitcoin with S\&P500 RV, GFSI, GSCI RV, CEPU, GREA, and the naive forecast combination. The errors are set relative to the simple GARCH prediction from June 29, 2015 to July 31, 2019. The "bear" market of 2018 to April 2019 is shaded in grey. 

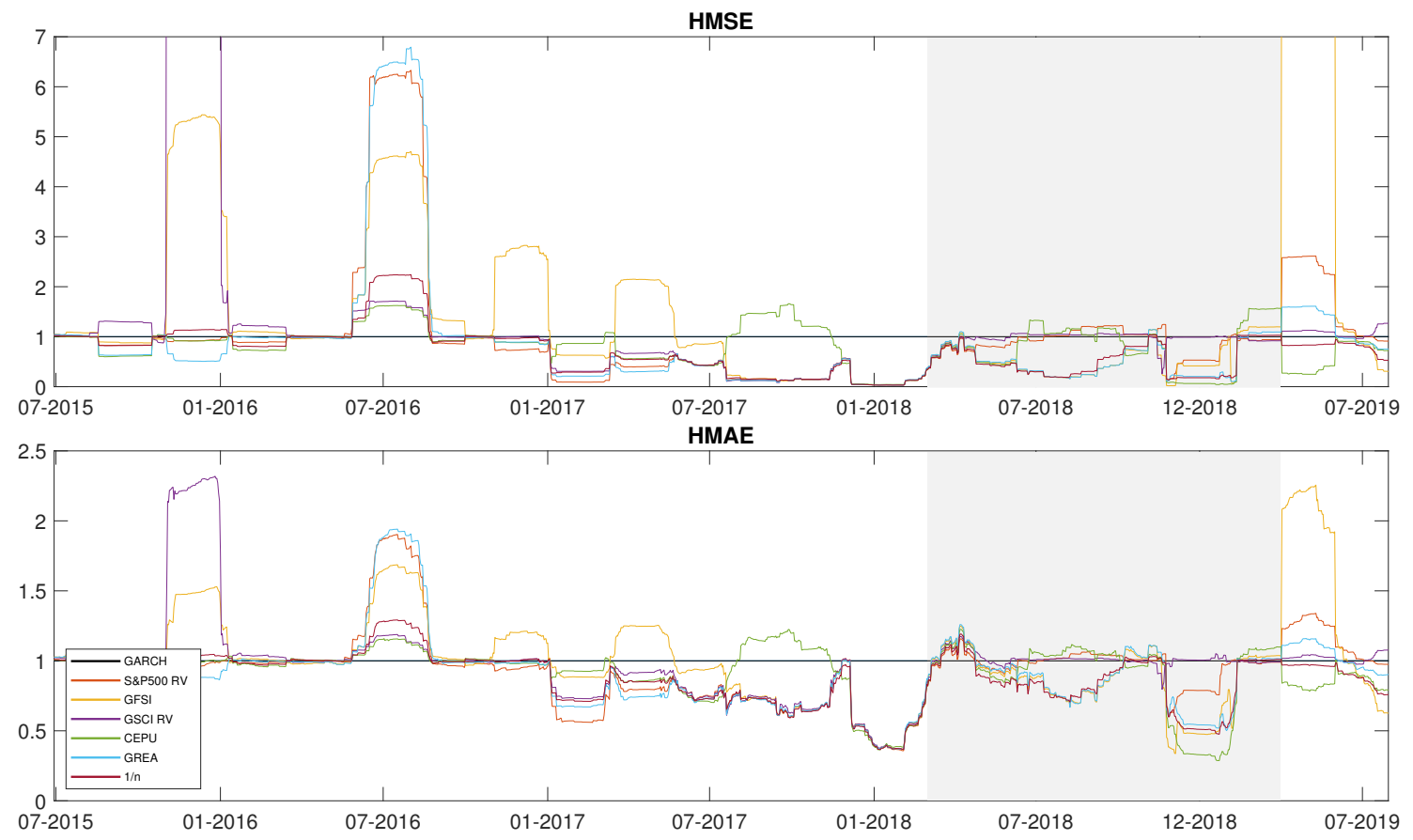

Figure 5: 60 days rolling window 30-days ahead relative HMSE and HMAE of Bitcoin with S\&P500 RV, GFSI, GSCI RV, CEPU, GREA, and the naive forecast combination. The errors are set relative to the simple GARCH prediction from June 29, 2015 to July 31, 2019. The "bear" market of 2018 to April 2019 is shaded in grey.
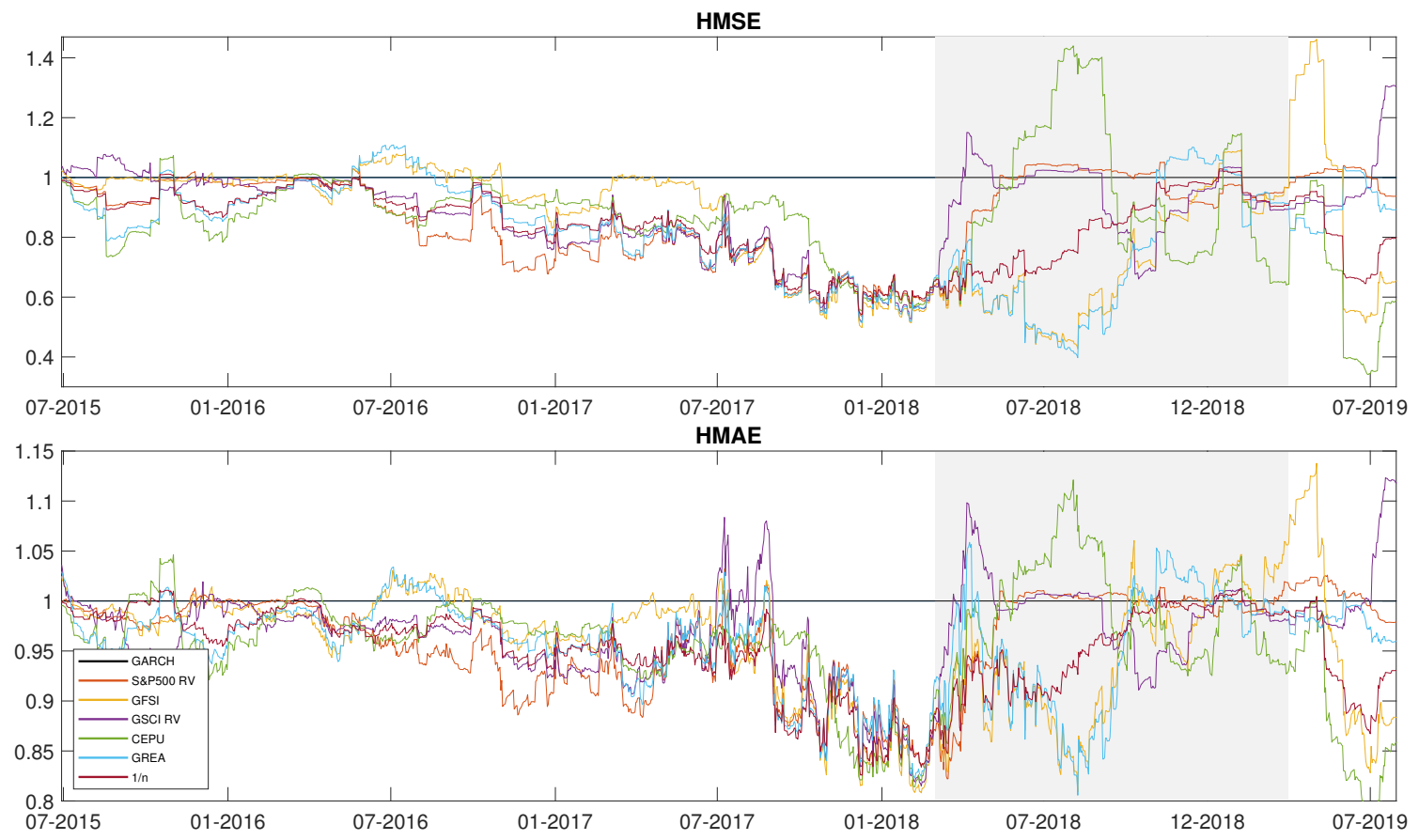

Figure 6: 60 days rolling window 1-day ahead relative HMSE and HMAE of CRIX with S\&P500 RV, GFSI, GSCI RV, CEPU, GREA, and the naive forecast combination. The errors are set relative to the simple GARCH prediction from September 29, 2016 to July 31, 2019. The "bear" market of 2018 to April 2019 is shaded in grey. 

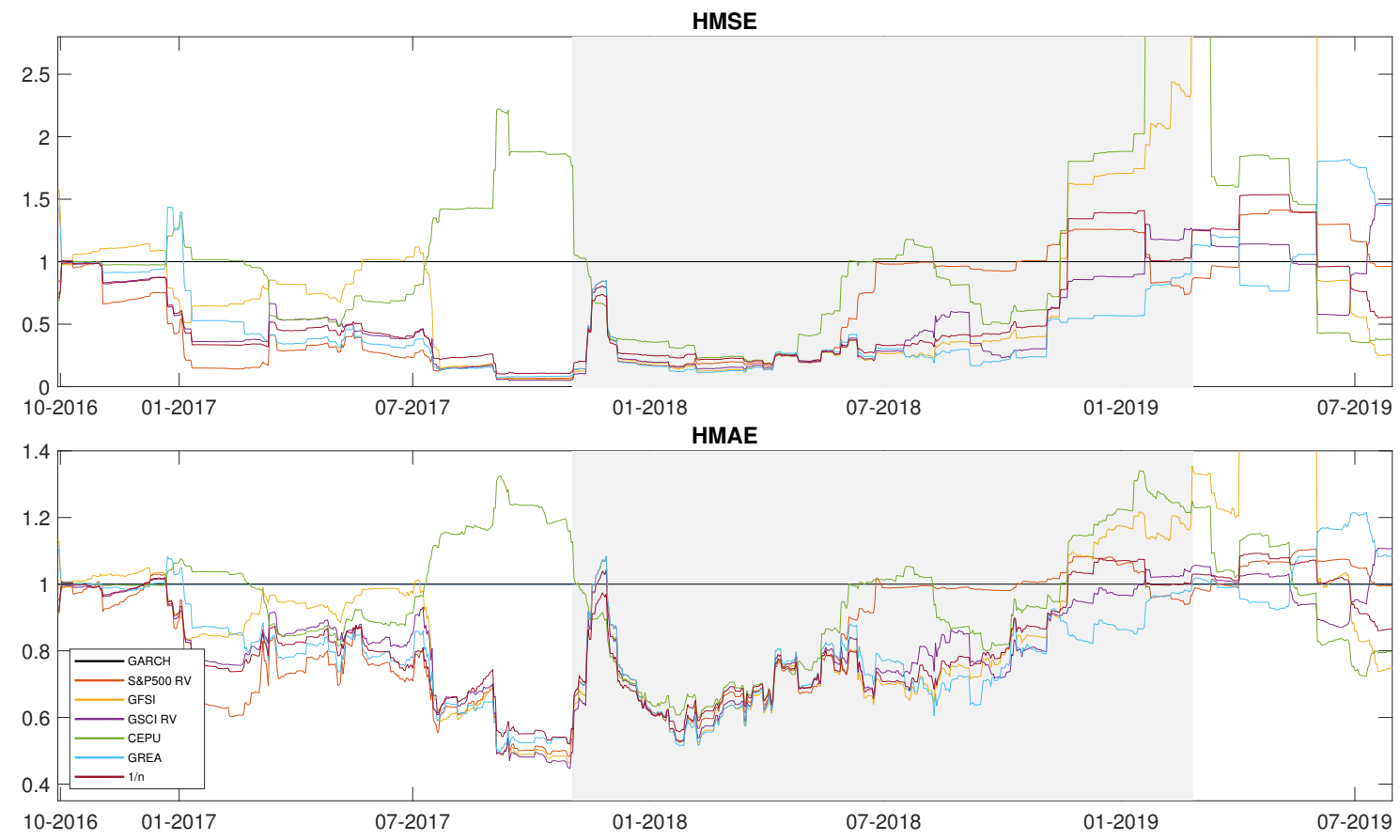

Figure 7: 60 days rolling window 7-days ahead relative HMSE and HMAE of CRIX with S\&P500 RV, GFSI, GSCI RV, CEPU, GREA, and the naive forecast combination. The errors are set relative to the simple GARCH prediction from September 29, 2016 to July 31, 2019. The "bear" market of 2018 to April 2019 is shaded in grey.
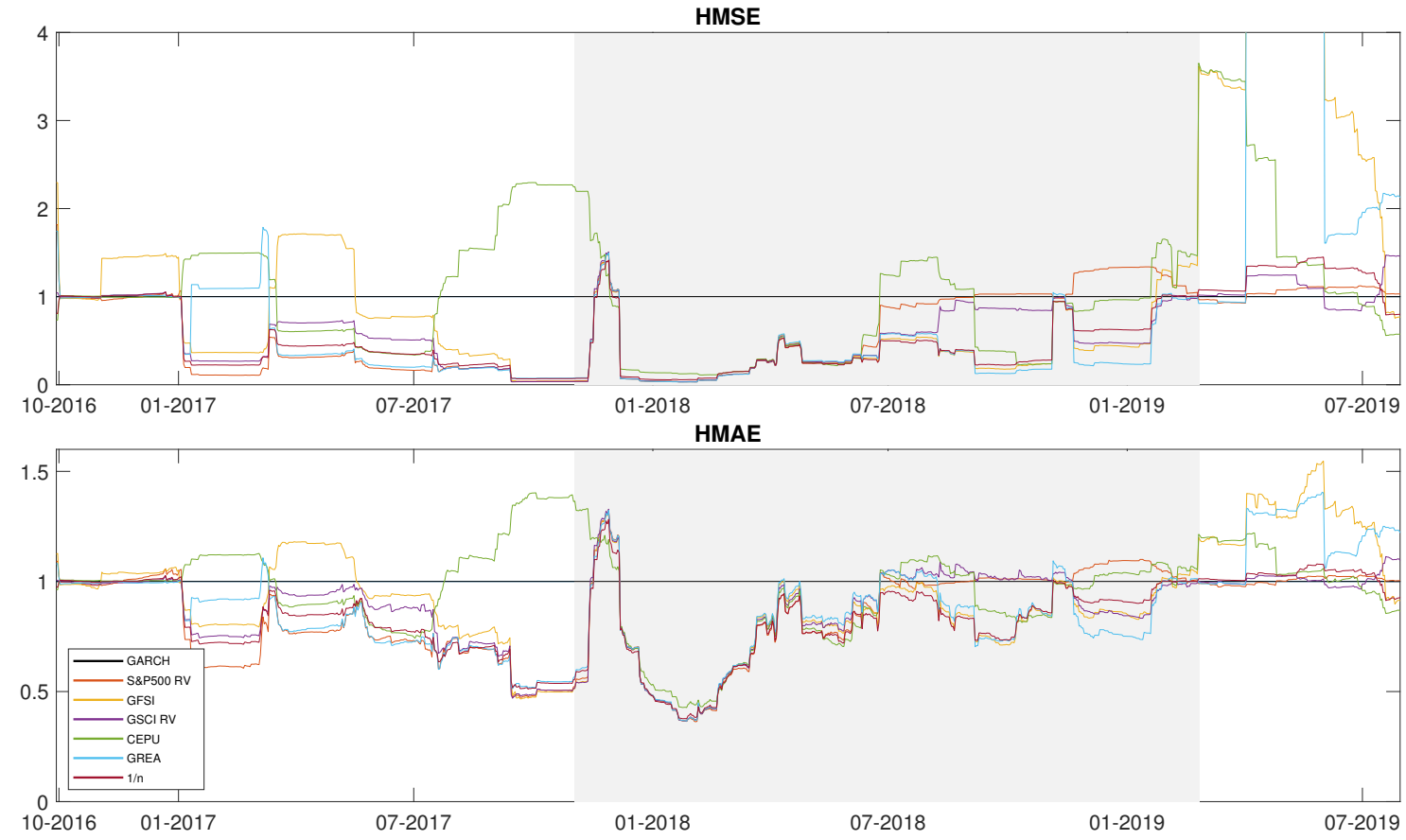

Figure 8: 60 days rolling window 30-days ahead relative HMSE and HMAE for CRIX with S\&P500 RV, GFSI, GSCI RV, CEPU, GREA, and the naive forecast combination. The errors are set relative to the simple GARCH prediction from September 29, 2016 to July 31, 2019. The "bear" market of 2018 to April 2019 is shaded in grey. 


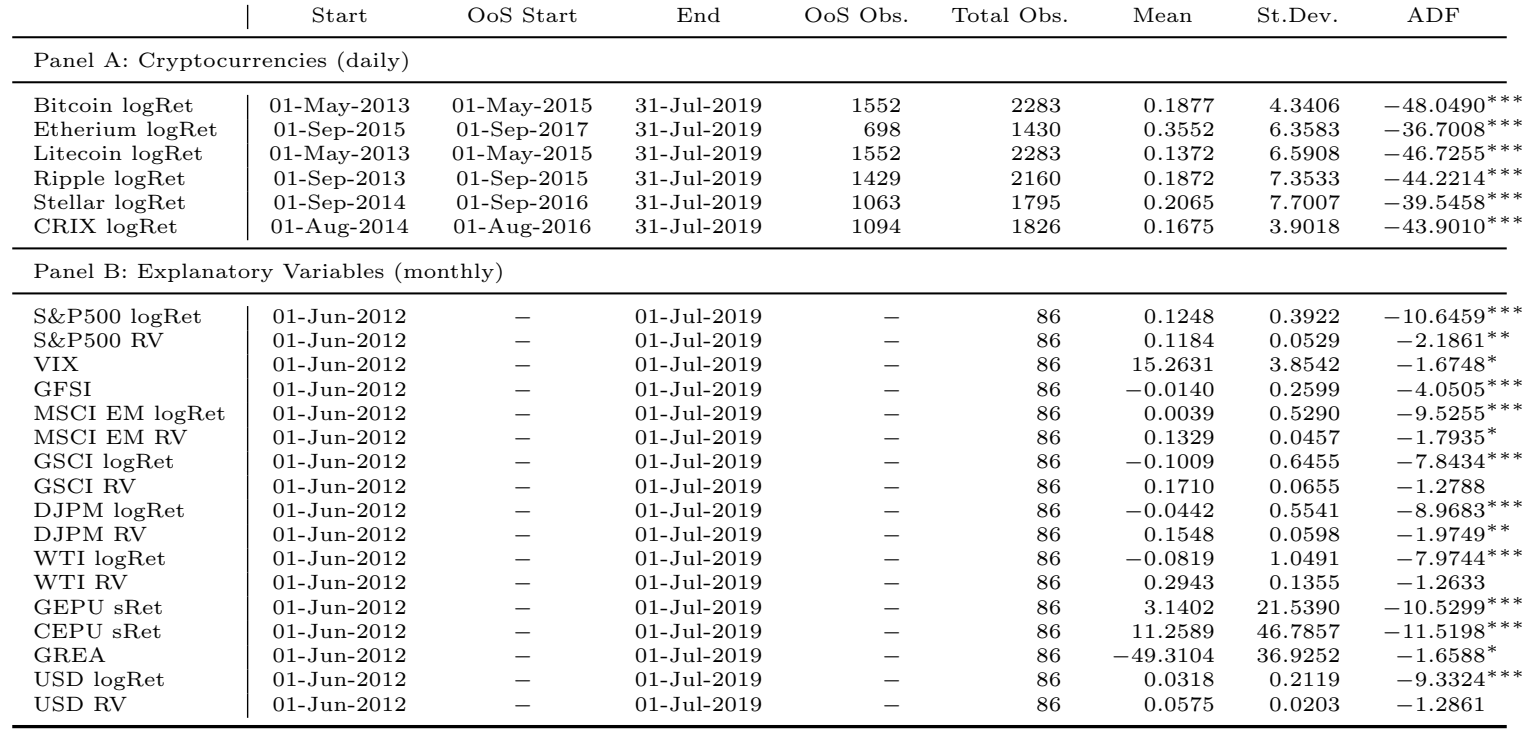

Table 1: Descriptive statistics of the daily return series of Cryptocurrencies and the monthly explanatory variables. OoS refers to the Out-of-Sample, Obs. are the number of observations, St.Dev. is the Standard Deviation, ADF is the Augmented-Dickey-Fuller-test for unit roots, logRet is the logarithmic return, sRet is the simple return or growth rate, and $\mathrm{RV}$ refers to the realized variance. The asterisks ${ }^{* * *},{ }^{* *}$, and ${ }^{*}$ correspond to the level of significance of $1 \%, 5 \%$, and $10 \%$. 

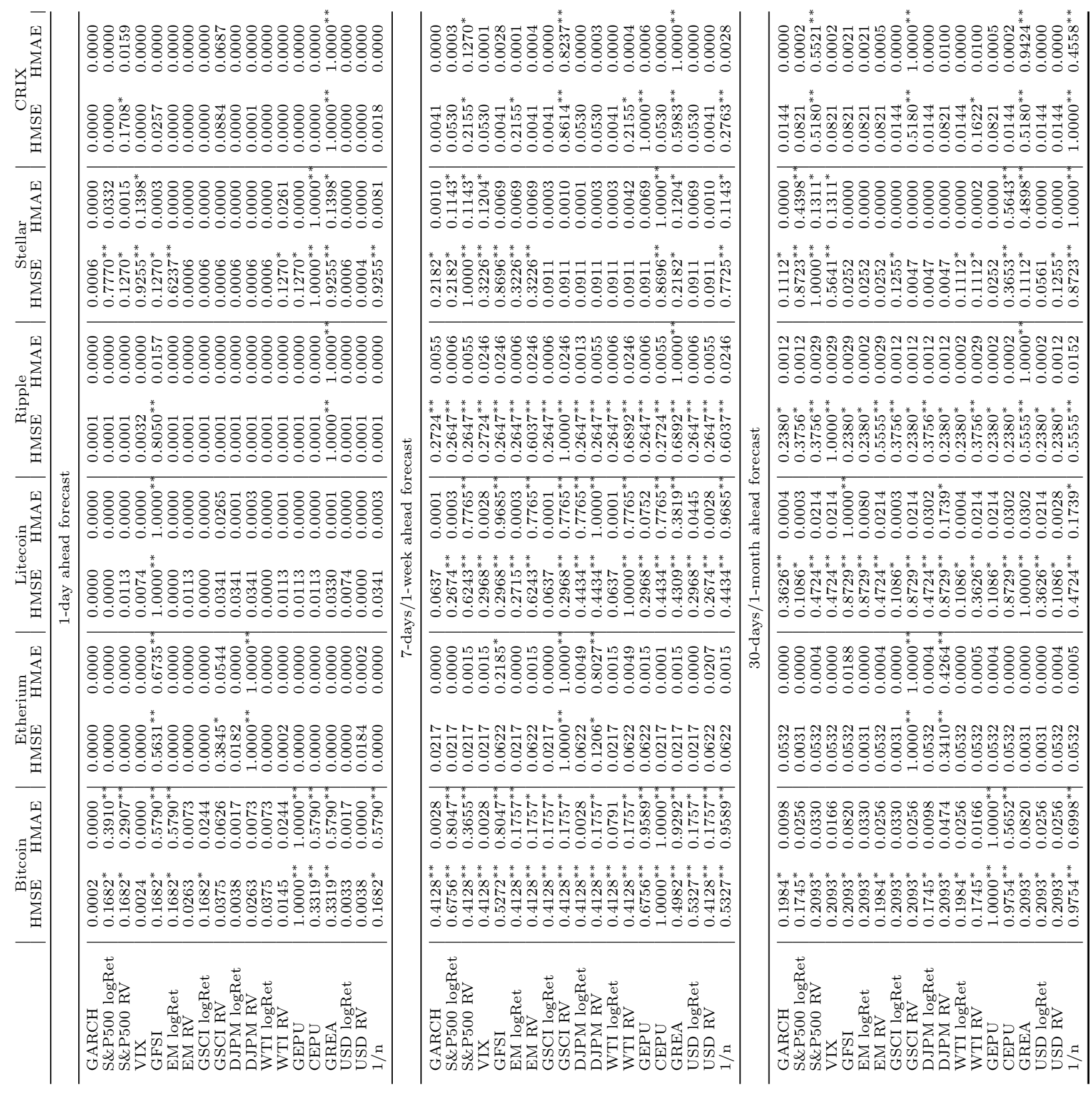

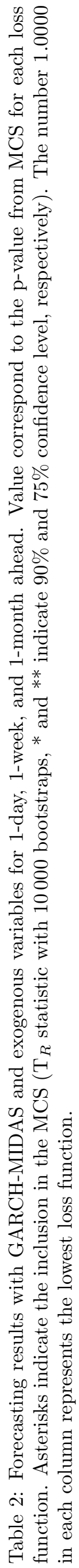

